\title{
ATRIBUTOS FÍSICO-HÍDRICOS DE UM ARGISSOLO AMARELO SOB FLORESTA E SAVANA NATURAIS CONVERTIDAS PARA PASTAGEM EM RORAIMA ${ }^{(1)}$
}

\author{
Diego Lima de Souza Cruz ${ }^{(2)}$, José Frutuoso do Vale Júnior ${ }^{(3)}$, Pablo Lima de Souza \\ Cruz ${ }^{(2)}$, Anna Bárbara de Souza Cruz ${ }^{(4)}$ \& Pedro Paulo Ramos Ribeiro Nascimento ${ }^{(4)}$
}

RESUMO

O Estado de Roraima apresenta ampla diversidade pedológica e de ecossistemas, sendo gradativamente ocupados com pastagem, que dependendo do manejo podem estar associadas à degradação física do solo. Dentro desse contexto, este trabalho foi realizado com os objetivos de avaliar e comparar os atributos físico-hídricos de um Argissolo Amarelo sob os ecossistemas de savana e floresta natural, convertidos em pastagem para pecuária. Os tratamentos principais foram savana natural (SN), savana convertida em pastagem (SC), floresta natural (FN) e floresta convertida em pastagem (FC) e os tratamentos secundários foram as profundidades de amostragem do solo, 0-10, 10-20 e 20-40 cm. Os atributos avaliados foram: granulometria, densidade do solo (DS) e de partículas (DP), resistência à penetração $(\mathrm{RP})$, porosidade total $(\mathrm{PT})$, umidade gravimétrica (UG), capacidade de armazenamento de água (CAD) e matéria orgânica do solo (MOS). A DS foi superior nas duas áreas de Savana, não havendo diferença entre SC e SN em nenhuma das profundidades. A RP variou em função das áreas e da profundidade, verificando-se influência da conversão nesse atributo. A PT foi maior na FN e menor na SC; houve diminuição da porosidade com a profundidade. A CAD foi maior na FN apenas na profundidade de 0-10 cm. A MOS foi superior nas áreas de FN e FC. Portanto, a conversão dos ambientes naturais em pastagem provocou alterações significativas na RP, DS, CAD, PT e MOS, com maior expressividade nas áreas da FC em razão da supressão da cobertura vegetal natural, que tem na matéria orgânica o condicionador da qualidade físico-hídrica do solo. Na SC, por sua vez, a supressão da cobertura vegetal natural não provocou a mesma expressividade por causa dos teores significativamente inferiores de MOS.

Termos de indexação: manejo do solo, qualidade física, Amazônia.

(1) Parte da Dissertação de Mestrado do primeiro autor. Recebido para publicação em 26 de abril de 2013 e aprovado em 3 de outubro de 2013.

(2) Mestre em Agronomia pelo Programa de Pós-Graduação em Agronomia - POSAGRO, Universidade Federal de Roraima UFRR. BR 174, s/n. CEP 69304-000 Boa Vista (RR). E-mail: diegocruzali@gmail.com, pablocruz@hotmail.com.br

(3) Professor Associado II, Centro de Ciências Agrárias, UFRR. E-mail: valejr51@gmail.com

(4) Bolsista de Iniciação Científica - PIBIC/CNPq, UFRR. E-mail: pedonpaulo@hotmail.com, barbarammc@gmail.com 


\title{
SUMMARY: PHYSICAL AND WATER PROPERTIES OF AN ULTISOL UNDER NATURAL FOREST AND SAVANNA AND PLANTED TO PASTURE IN RORAIMA, BRAZIL
}

\begin{abstract}
The broad soil and ecosystem diversity of the state of Roraima is gradually being replaced by pasture and, depending on the management system adopted, this can be associated with soil physical degradation. Within this context, the aim of the present study was to evaluate and compare the soil physical attributes of an Argissolo Amarelo (Ultisol) under savanna and forest natural ecosystems, and their conversion into a cattle pasture system. The primary treatments were natural savanna (NS), savanna converted to pasture (CS), natural forest (NF) and forest converted to pasture (CF). The secondary treatments were the soil sampling depths of 0-10,10-20 and 20-40 cm. The following physical properties were evaluated: texture, bulk density $(S D)$ and particle density $(P D)$, resistance to penetration $(P R)$, total porosity $(T P)$, gravimetric moisture (GM), available water capacity (AWC), and soil organic matter (SOM). The $S D$ was greater in both savanna areas, without differences between CS and NS at any depth, associated with the cohesive character of savanna soils. The average PD value was typical of kaolinite soils. PR varied as a function of the areas and the depths; the effect of conversion on this property was observed. TP was greater in NF and less in CS, and TP decreased along with depth. AWC was greater in NF only at the $0-10 \mathrm{~cm}$ depth. SOM was greater in the NF and CF areas. The study concluded that conversion of the natural environment into pasture systems caused significant changes in PR, SD, AWC, TP and SOM, with major expressiveness in $C F$, due to the removal of natural vegetation, leading to the loss of SOM, which is an important conditioner of soil physical and water properties. In CS areas, suppression of the natural vegetation did not lead to the same expressiveness, mainly due to the significantly lower SOM contents.
\end{abstract}

Index terms: soil management, physical quality, Amazon.

\section{INTRODUÇÃO}

A diversidade pedológica do Estado de Roraima abrange as 13 classes do solo do Sistema Brasileiro de Classificação de Solos (SiBCS) (Embrapa, 2013). Em sua maioria são solos com avançado grau de intemperismo, cujo resultado provém principalmente da ação do clima úmido e do material de origem composto por sedimentos pré-intemperizados. Também são encontrados todos os tipos de relevo, que determinam padrões de drenagem marcantes, a exemplo do hidromorfismo (Vale Júnior \& \& Schaefer, 2010). Ocorrem materiais de origem como sedimentos aluviais, sedimentos argiloarenosos da formação Boa Vista, sienitos, arenitos, siltitos, granitos, gnaises e rochas vulcânicas ácidas, básicas (basalto) e diabásios (Melo et al., 2004). Sobre a diversidade de materiais de origem e de geomorfologia se inserem empreendimentos agrícolas como a pecuária, piscicultura, fruticultura e a cultura de grãos como soja e milho.

A atividade pecuária tem sido relacionada com diversos casos de perda da qualidade física do solo, sendo a pressão exercida pelo pisoteio animal a responsável pelo aumento da densidade do solo (Alves et al., 2007). A qualidade física está associada àquele solo que permite a infiltração, retenção e disponibilização de água às plantas, responde ao manejo e resiste à degradação, permite as trocas de calor e de gases com a atmosfera e as raízes de plantas, culminando no desenvolvimento adequado dos vegetais (Alves et al., 2007).
Os impactos do uso e manejo na qualidade física do solo têm sido quantificados na tentativa de compreender essa dinâmica. São utilizados atributos físicos como granulometria, densidade do solo, porosidade do solo, resistência do solo à penetração e taxa de infiltração, entre outros (Costa et al., 2003; Cruz et al., 2003; Silva et al., 2005; Cavalieri et al., 2006; Carneiro et al., 2009).

A granulometria do solo é um dos atributos mais estáveis, sendo modificada levemente pelo cultivo e pelas outras práticas que ocasionam a mistura de diferentes profundidades. Contudo, é uma propriedade que tem estreita relação com a retenção e o transporte de água, a estrutura do solo, a retenção de nutrientes e de matéria orgânica, além de influenciar fortemente os processos erosivos do solo (Barros et al., 2009). A granulometria interfere em vários atributos físicohídricos do solo. Silveira et al. (2010) verificaram que pequenas alterações no conteúdo de água determinam grandes variações na resistência à penetração.

A densidade do solo inclui o espaço compreendido dentro dos agregados e entre os agregados, isto é, leva em consideração o espaço poroso do solo, refletindo bem as suas condições estruturais bem como a textura, que em grande parte sofre influência do manejo adotado (Amaro Filho et al., 2008).

Para a qualidade física, a resistência do solo à penetração é considerada por Silveira et al. (2010) e Santana et al. (2006) a propriedade mais adequada para expressar o grau de compactação do solo e, 
consequentemente, a facilidade de penetração das raízes. Conforme Flores et al. (2007), a pressão exercida sobre o solo é o agente causador da compactação e há evidências de que a compactação superficial está relacionada a essa pressão exercida pelo pisoteio animal; já a compactação subsuperficial está mais relacionada à carga total aplicada por eixo das máquinas agrícolas, independentemente da pressão exercida sobre a superfície.

Em Roraima, Souza (2010) encontrou diferença na RP de um Argissolo Vermelho-Amarelo sob floresta e pastagem, sendo observados valores respectivos de 0,41 e 1,48 $\mathrm{MPa}(0-10 \mathrm{~cm}), 1,61$ e 2,26 $\mathrm{MPa}(10-20 \mathrm{~cm})$ e 2,39 e $2,75 \mathrm{MPa}(20-40 \mathrm{~cm})$. Por sua vez, Barros et al. (2009) avaliaram a RP em um Argissolo VermelhoAmarelo sob savana natural de Roraima, encontrando os valores de $1,48 \mathrm{MPa}(0-20 \mathrm{~cm})$ e $2,84 \mathrm{MPa}(20-40 \mathrm{~cm})$. A menor RP observada na floresta natural é resultado da interação dos atributos físico-hídricos do solo, que se inter-relacionam com fatores ambientais e características da cobertura vegetal. Essas relações foram abordadas por Martins et al. (2003) que elencaram fatores encontrados na floresta que contribuem para a menor susceptibilidade de degradação do solo, como a interceptação das gotas de chuva pelo dossel da mata; a existência de uma espessa camada de folhas (serapilheira); os maiores teores de matéria orgânica, condicionando agregados de maior estabilidade, melhor estruturação e maior permeabilidade da água no solo; e a ausência formas de compactação do solo que confiram menores valores de RP (Silva et al., 2005).

Valores de RP acima de 2,0 MPa são considerados críticos para o desenvolvimento radicular (Arshad \& Martins, 2002), embora os de 2,5 MPa, para pastagens (Leão, 2002); 3,0 MPa, para floresta; e 3,5 $\mathrm{MPa}$, para Sistema de Plantio Direto (Giarola et al., 2007) tenham sido relacionados como críticos. Taylor et al. (1966) observaram que a penetração das raízes pivotantes do algodão através de amostras de solo de $25 \mathrm{~mm}$ foi próximo a zero, quando a resistência à penetração foi acima de $2 \mathrm{MPa}$. A resistência do solo à penetração do cone de $2 \mathrm{MPa}$ é frequentemente utilizada como critério de compactação excessiva para o crescimento das plantas para ensaios realizados com o solo com conteúdo de água próximo à capacidade de campo.

A porosidade é reduzida nos horizontes coesos e compactados e tem sido correlacionada com a granulometria e a densidade do solo (Santana et al., 2006). As características de retenção de água no solo são substancialmente influenciadas pela porosidade $\mathrm{e}$ pela distribuição do tamanho de partículas do solo e pelo arranjo dessas. Dessa forma, o solo bem-manejado, com uso controlado do peso de maquinário, sem superpastejo, rotação por meio de piquetes e lotação animal adequada, tem como característica a boa qualidade físico-hídrica, que é refletida na retenção e permeabilidade de água no solo (Silva, 2005).
Existem poucos artigos científicos sobre a qualidade físico-hídrica de solos na Amazônia, o que dificulta a comparação de resultados e o estabelecimento de índices críticos para essas propriedades. Destacam-se os trabalhos de Neves Júnior (2005); Moraes et al. (1996); Araújo (2008); Barros et al. (2009); Souza (2010); Benedetti et al. (2011). Assim, este trabalho teve por objetivos avaliar e comparar os atributos físicohídricos de um Argissolo Amarelo sob os ecossistemas de savana e floresta natural, convertidos em pastagem para pecuária.

\section{MATERIAL E MÉTODOS}

Este estudo foi realizado no Estado de Roraima, no período de março de 2011 a julho de 2012 . Uma área não antropizada, representativa do ecossistema floresta natural (FN), foi determinada no município de Rorainópolis (vicinal 09), nas coordenadas UTM N0783832 e W00930008. Nas adjacências, foi selecionada uma área de floresta convertida à pastagem para pecuária (FC), cujas coordenadas são UTM N0783816 e W0092996. Selecionou-se uma área não antropizada de savana natural (SN) no município de Bonfim à margem da BR-410 a aproximadamente $20 \mathrm{~km}$ da capital Boa Vista. Para a área de savana convertida (SC), foi selecionada uma área de pastagem para pecuária na Fazenda Smith, que se distanciava da $\mathrm{SN}$ em aproximadamente $4 \mathrm{~km}$.

O solo estudado nas duas áreas foi classificado como Argissolo Amarelo distrófico sob floresta e Argissolo Amarelo distrocoeso em savana; o relevo na savana foi de plano a suave ondulado (5 a $10 \%$ ) e na floresta, suave ondulado a ondulado ( 8 a $13 \%$ ). A classe textural do solo sob floresta convertida e natural é francoargiloarenosa, até a profundidade de $20 \mathrm{~cm}$ e de 20-40 cm, arenoargilosa. Na savana (natural e convertida), a classe textural é franco-arenosa até a profundidade de $20 \mathrm{~cm}$ e de $20-40 \mathrm{~cm}$ foi francoargiloarenosa. São solos profundos, bem drenados, com presença de plintita a partir de $30 \mathrm{~cm}$ de profundidade apenas na floresta, não sendo suficiente para diagnóstico de Plintossolo; possuem indicativo de formação desses solos a partir da destruição das cangas lateríticas, abundantes na região.

Segundo a classificação climática de Köppen, o Estado de Roraima apresenta o tipo Af, que é constantemente úmido, ocorrendo na região de florestas tropicais no sul do Estado; e o tipo Aw, que apresenta um regime hídrico bem diferenciado, com uma estação seca e uma estação chuvosa de aproximadamente seis meses, abrangendo as savanas (Barbosa, 1997).

A SC é uma área que teve a vegetação nativa substituída por plantio de Brachiaria brizantha (cultivar Marandu), que ocorreu há 5 anos por meio do uso de uma aração e uma gradagem, com trator 
New Holland TT 4030 (75 cv), peso (com lastro) de $3.800 \mathrm{~kg}$ mais $1.500 \mathrm{~kg}$ da grade aradora. A taxa de lotação animal foi de um animal por hectare (1 UA), sem sistema de piqueteamento para a rotação de pastagem. A média de peso animal foi de $250 \mathrm{~kg}$, com animais da raça Nelore de aproximadamente 36 meses de idade, que permaneceram durante todo o ano, não sendo realizado qualquer controle sobre a entrada e saída do gado nos períodos seco e chuvoso. A área de SN foi classificada como Savana Parque, não antropizada, com predominância de Caimbés (Curatela americana) e gramíneas da espécie Trachypogon vestitus (Costa et al., 2012).

A FN foi classificada como Floresta Ombrófila Densa. A FC foi desmatada há aproximadamente 25 anos pelo uso do fogo e destoca mecanizada. Há 16 anos essa área tem sido ocupada com Brachiaria brizantha (cultivar Marandu) e criação de bovinos; foi instalada por meio de uma aração e uma gradagem, com trator New Holland TL 85, peso de $3.400 \mathrm{~kg}$, mais grade aradora de $1.500 \mathrm{~kg}$. A taxa de lotação animal também foi de um animal por hectare (1 UA), sem sistema de piqueteamento. A média de peso animal foi de $250 \mathrm{~kg}$, sendo composta por $80 \%$ de novilhos da raça Nelore. Os animais também permaneceram na área durante todo o ano.

As pastagens na $\mathrm{SC}$ e FC foram manejadas de forma semelhante, com apenas uma calagem e adubação, uma aração e uma gradagem no início do plantio; não foi realizada nenhuma roçada e não houve controle de entrada e saída de animais. A cultivar Marandu foi plantada nas duas áreas, sendo a semeadura realizada a lanço $\left(10 \mathrm{~kg} \mathrm{ha}^{-1}\right)$. Trata-se de uma planta perene, cespitosa, muito robusta, com produção de matéria seca, em ambiente amazônico, em torno de 1,6 t ha ${ }^{-1}$ no período seco e $3,3 \mathrm{t} \mathrm{ha}^{-1}$ no período chuvoso, podendo atingir mais $95 \%$ de cobertura do solo (Oliveira et al., 2007; Cruz, 2010). A pastagem nativa em SN (Trachypogon vestitus) apresenta produção média de $1.000 \mathrm{~kg} \mathrm{ha}^{-1}$ de matéria seca e baixas taxas de crescimento e cobertura do solo, quando comparadas com cultivares comercias de $B$. brizantha (Costa et al., 2012).

O delineamento experimental foi em blocos casualizados, em esquema de parcela subdividida com cinco blocos. As parcelas foram compostas por quatro áreas: A1: Floresta Natural (FN), A2: Savana Natural (SN), A3: Floresta convertida em pastagem para bovinos (FC) e A4: Savana convertida em pastagem para pecuária (SC). As subparcelas foram compostas por três profundidades de amostragem: P1: 0-10, P2: 10-20 e P3: $20-40 \mathrm{~cm}$. As variáveis analisadas foram a granulometria, densidade do solo (DS), densidade de partículas (DP), resistência à penetração (RP), umidade gravimétrica do solo (UG), porosidade total (PT), matéria orgânica do solo (MOS) e capacidade de água disponível (CAD).

As amostras para análises físico-hídricas foram obtidas de cinco minitrincheiras (consideradas as repetições) com $50 \mathrm{~cm}$ de profundidade, distribuídas na área de cada tratamento (1 ha). Em cada minitrincheira foram coletadas amostras deformadas e indeformadas (amostrador de Uhland com $104 \mathrm{~cm}^{3}$ ). Determinou-se a resistência à penetração em campo utilizando-se o penetrômetro de pressão da marca Solotest, em cinco leituras nas três profundidades. Portanto, cada tratamento teve 15 amostras deformadas e 15 indeformadas e 75 leituras de RP.

Das amostras deformadas, foram preparadas as de terra fina seca ao ar (TFSA). Parte das amostras indeformadas foi acondicionada em latas de alumínio para determinar a umidade gravimétrica e a densidade do solo no laboratório de solos da UFRR. As amostras de TFSA e o restante das amostras indeformadas foram enviados ao Laboratório de Física do Solo da Universidade Federal de Viçosa para as demais análises físico-hídricas, de acordo com Embrapa (1997). Foi realizada análise de retenção de umidade em três potenciais mátricos $(-0,10$. $-0,30$ e $-1.500 \mathrm{kPa}$ ) para a determinação da CAD e comparação com a UG, para constatar a umidade na capacidade de campo nas áreas observadas.

Os dados foram avaliados pelo Teste $\mathrm{F}$ com o intuito de observar efeito das parcelas (áreas), das subparcelas (profundidades) e da interação entre área e profundidade sobre as médias. Constatado o efeito significativo pelo teste $\mathrm{F}$, procedeu-se o teste comparativo entre médias pelo teste de Tukey a $5 \%$, empregando-se o programa SAEG (Ribeiro Júnior, 2004).

\section{RESULTADOS E DISCUSSÃO}

Conforme os resultados da granulometria, os solos estudados são predominantemente de textura média, com maior proporção de areia e maior expressão do gradiente textural nas áreas de savana (Quadro 1), associado principalmente ao material de origem que são sedimentos argiloarenosos da formação Boa Vista; nas áreas de floresta, os Argissolos Amarelos apresentam características que indicam evolução a partir da destruição de cangas lateríticas, imprimindo caráter plíntico ou petroplíntico a esses solos.

A densidade do solo (DS) foi estatisticamente superior nas duas áreas de Savana, não havendo diferença entre Savana Convertida e Savana Natural em nenhuma profundidade do solo (Quadro 2). Esse resultado pode estar associado à coesão natural entre a profundidade de $20-40 \mathrm{~cm}$ em Argissolos Amarelos sob savana de Roraima, conforme estudos de Benedetti et al. (2011), em que foram classificados como distrocoesos no terceiro nível categórico do SiBCS (Embrapa, 2013). Foi observado aumento significativo da DS na FC na profundidade superficial até $10 \mathrm{~cm}$ do solo; nas maiores profundidades não houve diferença entre FN e FC (Quadro 3). Esse resultado pode estar associado à perda significativa da matéria orgânica 
Quadro 1. Granulometria do solo em áreas de floresta e savana naturais e convertidas em pastagem, nas três profundidades avaliadas

\begin{tabular}{lcccc}
\hline Tratamento & Argila & Silte & Areia & RT $^{(\mathbf{1})}$ \\
\cline { 2 - 4 } & \multicolumn{3}{c}{ dag kg ${ }^{-1}$} & 0-10 cm \\
& & 11 & 64 & 1,6 \\
Floresta natural & 23 & 7 & 66 & 1,9 \\
Floresta convertida & 26 & 11 & 78 & 2,2 \\
Savana natural & 11 & 8 & 81 & 2,1 \\
Savana convertida & 10 & $10-20 \mathrm{~cm}$ & & \\
& & 10 & 62 & \\
Floresta natural & 28 & 6 & 57 & \\
Floresta convertida & 37 & 11 & 70 & \\
Savana natural & 19 & 8 & 75 & \\
Savana convertida & 17 & 9 & 59 & \\
& & $20-40 \mathrm{~cm}$ & & \\
Floresta natural & 36 & 4 & 50 & \\
Floresta convertida & 48 & 6 & 71 & \\
Savana natural & 22 & 11 & 67 & \\
Savana convertida & 22 & 6 & & \\
\hline
\end{tabular}

(1) RT: Relação textural entre as profundidades de 0-10 e 20-40 cm.

nessa profundidade, que promove desestabilização à estrutura do solo pela pressão causada pelo tráfego de maquinário e pelo pisoteio animal.

Valores críticos de DS foram observados por Lima et al. (2007) em Argissolo Vermelho distrófico, onde esse atributo teve correlação positiva com a RP e negativa com a umidade do solo. Esses autores observaram que, adotando-se a $\mathrm{RP}=1,50 \mathrm{MPa}$, valores de densidade superiores a $1,69 \mathrm{~g} \mathrm{~cm}^{-3}$ podem ser restritivos ao crescimento radicular. Quando considerada uma $\mathrm{RP}=2 \mathrm{MPa}$, a densidade crítica (DSc) na umidade na capacidade de campo $\left(\theta_{\mathrm{CC}}\right)$ foi de $1,76 \mathrm{~g} \mathrm{~cm}^{-3}$ e na umidade no ponto de murcha permanente $\left(\theta_{\mathrm{PMP}}\right)$, de $1,44 \mathrm{~g} \mathrm{~cm}^{-3}$. Ao comparar os dados obtidos por esses autores com os observados neste trabalho, verificou-se que apenas as áreas de savana apresentaram RP superior a $1,50 \mathrm{MPa}$ de $0-10 \mathrm{~cm}$ de profundidade. Com o aumento da profundidade de amostragem, ocorreu elevação nos valores de RP, porém sem extrapolar o valor de DS considerado crítico por esses autores.

Entretanto, ainda faltam estudos para a determinação de valores críticos de atributos físicohídricos na Amazônia. As áreas de savana apresentaram menores alterações pela conversão de ambiente natural para sistema de pastagem para pecuária do que as áreas de floresta, porém não resultou em melhores condições físico-hídricas. A DS superior nas áreas de savana pode estar associada à maior frequência dos ciclos de umedecimento e secagem, pois nessa região registram-se períodos secos mais longos, combinado com menores teores de MOS, influenciando negativamente na estrutura e estabilidade de agregados (Benedetti et al., 2011).
Ao contrário do observado neste estudo, Benedetti et al. (2011) não observaram diferença entre a DS do horizonte A $(0-25 \mathrm{~cm})$ e do $\mathrm{Bt}(43-105 \mathrm{~cm})$ de um Argissolo Amarelo sob savana de Roraima, cujo valor foi inferior ao encontrado neste estudo. Quanto à $\mathrm{DP}$, o valor médio encontrado neste trabalho foi de $2,66 \mathrm{~g} \mathrm{~cm}^{-3}$ e é característico de solos cauliníticos (Amaro Filho et al., 2008), que é associado à natureza pré-intemperizada dos sedimentos da Formação Boa Vista.

Já em ambiente de floresta, Souza (2010) também constatou em um Argissolo Vermelho-Amarelo de Roraima que a DS da floresta foi menor que a da pastagem até os $10 \mathrm{~cm}$. Esse autor observou valores que evidenciaram que a compactação do solo pelo pisoteio é superficial, dado corroborado neste trabalho.

Não houve diferença significativa da RP na SC e SN em nenhuma profundidade, podendo estar associada à igualdade nos valores de $\mathrm{DS}$ e de umidade $\left(0,11 \mathrm{~g} \mathrm{~g}^{-1}\right)$. A UG também não variou entre FN e FC; contudo, houve aumento da RP na FC, estando diretamente relacionada com o aumento da DS. A resistência de alguns ecossistemas a mudanças provocadas pelas atividades agrícolas é descrita por Neves Júnior (2005) e Lima et al. (2007); portanto, verificou-se que a FN é mais susceptível às alterações com o manejo.

Observou-se aumento significativo da RP com a profundidade, dado corroborado por Barros et al. (2009) e Souza (2010) O aumento considerável da RP a partir dos $20 \mathrm{~cm}$ observados no trabalho desses autores e neste trabalho pode estar associado ao topo do horizonte Bt, onde os teores de argila aumentam consideravelmente. Na profundidade de $20-40 \mathrm{~cm}$, não se observou diferença significativa entre as áreas.

Foi verificado valor crítico da RP na SN para a profundidade de $20-40 \mathrm{~cm}$ desse solo, conforme critérios de Taylor et al. (1966), Arshad \& Martins (2002) e Giarola et al. (2007). O efeito dessa RP foi observado em campo, pela concentração do sistema radicular das espécies arbóreas nos primeiros $40 \mathrm{~cm}$ de profundidade.

Em um padrão de resposta inversa, a PT teve valores superior na $\mathrm{FN}$ e inferior na SC, na profundidade de $0-10 \mathrm{~cm}$. Tais respostas podem estar intimamente relacionadas com o teor de MOS, que foi superior nas áreas de Floresta, especialmente na FN, diferindo estatisticamente da FC nas menores profundidades. Já entre as áreas de savana não houve diferença estatística significativa em nenhuma profundidade.

$\mathrm{A}$ área de $\mathrm{FN}$ foi a única que apresentou diferença significativa no teor de MOS nas três profundidades. Essa resposta provavelmente se dá pelo acúmulo de biomassa vegetal na superfície do solo, ocorrendo em maior grau nas florestas. Esse padrão é frequentemente evidenciado no trópico úmido, em especial nos solos brasileiros, conforme estudo já realizado por Neves Júnior (2005). 
Quadro 2. Resumo da análise de variância pelo teste de Fischer a 5 \%

\begin{tabular}{crrrrrr}
\hline \multirow{2}{*}{ Atributo } & \multicolumn{3}{c}{ QM } & & \multicolumn{2}{c}{ F } \\
\cline { 2 - 7 } & Área & Prof. & Área x prof. & Área & Prof. & Área x prof. \\
\hline DS & 0,66 & 0,081 & 0,035 & $150,0^{* *}$ & $44,45^{* *}$ & $19,44^{* *}$ \\
DP & 0,0032 & 0,020 & 0,020 & $0,27^{\text {ns }}$ & $1,81^{\text {ns }}$ & $1,81^{\text {ns }}$ \\
RP & 1129,1 & 1957,2 & 114,0 & $27,14^{* *}$ & $259,23^{* *}$ & $15,10^{* *}$ \\
UG & 0,090 & 0,0011 & 0,0022 & $37,5^{* *}$ & $3,66^{\text {ns }}$ & $7,33^{* *}$ \\
PT & 0,094 & 0,011 & 0,0060 & $62,66^{* *}$ & $11,76^{* *}$ & $6,18^{* *}$ \\
MOS & 14,90 & 7,51 & 1,46 & $45,15^{* *}$ & $41,72^{* *}$ & $8,11^{* *}$ \\
CAD & 30,90 & 24,24 & 3,15 & $10,06^{* *}$ & $13,02^{* *}$ & $1,69^{\text {ns }}$ \\
\hline
\end{tabular}

QM: Quadrado médio; F: Teste de Fischer; Área x Profundidade (Prof.): Interação; ${ }^{* *}$ significativa a $1 \%$; e ${ }^{\text {ns }}$ não significativo.

Quadro 3. Valores médios de densidade do solo (DS), resistência à penetração (RP), umidade gravimétrica (UG), porosidade total (PT), matéria orgânica do solo (MOS) e capacidade de água disponível (CAD), em razão dos tratamentos e das profundidades estudadas

\begin{tabular}{|c|c|c|c|c|c|c|}
\hline Tratamento & DS & $\mathbf{R P}$ & UG & PT & MOS & CAD \\
\hline & $\mathrm{g} \mathrm{cm}^{-3}$ & $\mathrm{MPa}$ & $\mathrm{g} \mathrm{g}^{-1}$ & $\mathrm{dm}^{3} \mathrm{dm}^{-3}$ & $\%$ & \\
\hline & \multicolumn{6}{|c|}{$0-10 \mathrm{~cm}$} \\
\hline Floresta natural & $1,03 \mathrm{Cc}$ & $0,39 \mathrm{Bc}$ & $0,30 \mathrm{~A}$ & 0,60 Aa & $4,20 \mathrm{Aa}$ & $10,64 \mathrm{Aa}$ \\
\hline Floresta convertida & $1,35 \mathrm{Ba}$ & $1,47 \mathrm{ABc}$ & $0,22 \mathrm{~A}$ & $0,49 \mathrm{Ba}$ & $2,53 \mathrm{Ba}$ & $7,34 \mathrm{Bb}$ \\
\hline Savana natural & $1,55 \mathrm{Ab}$ & $2,05 \mathrm{Ab}$ & $0,11 \mathrm{~B}$ & $0,41 \mathrm{BCa}$ & $0,94 \mathrm{Ca}$ & $5,92 \mathrm{Bb}$ \\
\hline \multirow[t]{2}{*}{ Savana convertida } & $1,65 \mathrm{Aa}$ & $2,54 \mathrm{Ac}$ & $0,11 \mathrm{~B}$ & 0,37 Ca & $1,02 \mathrm{Ca}$ & $6,06 \mathrm{Bb}$ \\
\hline & \multicolumn{6}{|c|}{$10-20 \mathrm{~cm}$} \\
\hline Floresta natural & $1,28 \mathrm{Bb}$ & $1,90 \mathrm{Bb}$ & $0,26 \mathrm{~A}$ & $0,50 \mathrm{Aa}$ & $2,66 \mathrm{Ab}$ & $9,84 \mathrm{Aa}$ \\
\hline Floresta convertida & $1,36 \mathrm{Ba}$ & $2,17 \mathrm{Bb}$ & $0,22 \mathrm{~A}$ & $0,50 \mathrm{Aa}$ & $1,86 \mathrm{Ab}$ & 7,80 Aab \\
\hline Savana natural & $1,66 \mathrm{Aa}$ & $3,84 \mathrm{Aa}$ & $0,11 \mathrm{~B}$ & $0,36 \mathrm{Ba}$ & $0,68 \mathrm{Ba}$ & 7,02 Ab \\
\hline \multirow[t]{2}{*}{ Savana convertida } & $1,69 \mathrm{Aa}$ & $4,32 \mathrm{Aa}$ & $0,11 \mathrm{~B}$ & $0,34 \mathrm{Ba}$ & 0,71 Bab & 7,34 Aab \\
\hline & \multicolumn{6}{|c|}{$20-40 \mathrm{~cm}$} \\
\hline Floresta natural & $1,38 \mathrm{Ba}$ & $3,13 \mathrm{Aa}$ & $0,23 \mathrm{~A}$ & 0,48 Aa & $1,45 \mathrm{Ac}$ & $10,70 \mathrm{Aa}$ \\
\hline Floresta convertida & $1,34 \mathrm{Ba}$ & $2,94 \mathrm{Aa}$ & $0,23 \mathrm{~A}$ & $0,48 \mathrm{Aa}$ & $1,37 \mathrm{ABb}$ & 9,90 Аa \\
\hline Savana natural & $1,66 \mathrm{Aa}$ & $4,07 \mathrm{Aa}$ & $0,12 \mathrm{~B}$ & $0,38 \mathrm{Ba}$ & 0,34 Ba & $9,52 \mathrm{Aa}$ \\
\hline Savana convertida & $1,67 \mathrm{Aa}$ & $3,77 \mathrm{Ab}$ & $0,11 \mathrm{~B}$ & $0,39 \mathrm{Ba}$ & $0,66 \mathrm{ABb}$ & $8,28 \mathrm{Aa}$ \\
\hline
\end{tabular}

Médias seguidas pela mesma letra maiúscula entre os tratamentos, na mesma profundidade, e médias seguidas pela mesma letra minúscula entre as profundidades, dentro de cada tratamento, não diferem entre si pelo teste de Tukey a $5 \%$.

O acúmulo de MOS no solo influencia em praticamente todos os atributos químicos e físicohídricos, conferindo maior estado de agregação/ estruturação, porosidade, retenção de umidade, menor densidade e resistência à penetração (Araújo, 2008), interação verificada nos resultados desta pesquisa, reforçando que os melhores sistemas para a recuperação de áreas degradadas são aqueles que favorecem a manutenção e o aumento dos teores de MOS, como as pastagens bem-manejadas.

Os teores de MOS observados nas áreas de pastagem deste estudo podem ter evitado mudanças mais drásticas nos atributos físico-hídricos do solo, fato corroborado por Flores et al. (2007), os quais não observaram diferenças estatísticas na porosidade nem na densidade com o pastejo intenso por bovinos.
A interação Áreas x Profundidade (Área x Prof.) não foi significativa para a CAD. Os efeitos das áreas sobre a CAD independem da profundidade e vice-versa. Portanto, observou-se a comparação entre as médias isoladamente em áreas e profundidade (Quadro 3).

A CAD foi estatisticamente maior na $\mathrm{FN}$ apenas na profundidade de $0-10 \mathrm{~cm}$, sendo o teor de MOS o atributo responsável pelo maior armazenamento de água. A remoção da vegetação natural no tratamento FC pode ter interferido nas propriedades físicas do solo, diretamente relacionadas com a CAD, a exemplo da densidade, porosidade e matéria orgânica (Araújo, 2008). Nas demais profundidades, a CAD de FN e FC foi estatisticamente igual; além disso, a área de FC apresentou aumento da CAD nas profundidades a partir de $20 \mathrm{~cm}$. 
Já entre as áreas de SN e SC, não foi observada diferença significativa, o que pode estar associado à manutenção da qualidade físico-hídrica do solo promovida pela pastagem, semelhantemente ao observado por Araújo (2008), o qual verificou em pastagens adubadas aumento nos teores de MOS, que, consequentemente, preservou essa qualidade. Também foi observado menor valor desse atributo nas profundidades mais superficiais da SC, o que pode estar relacionado à maior proporção de areia no Argissolo até $0 \mathrm{~s} 10 \mathrm{~cm}$ de profundidade.

\section{CONCLUSÕES}

1. A alteração significativa da DS, PT, MOS e CAD ocorreu apenas na área de FC; entretanto, nenhum valor para DS na FC foi considerado crítico ao desenvolvimento das plantas.

2. Entre as áreas de savana SN e SC não houve diferença estatística em nenhum atributo avaliado. Os valores observados também não foram considerados críticos ao crescimento das plantas.

3. As maiores alterações ocorreram em ambiente de floresta, associadas às maiores perdas da matéria orgânica do solo.

4. Os resultados indicaram que as áreas representativas de savana e floresta responderam diferentemente ao manejo das pastagens para pecuária, e os solos sob floresta apresentaram alterações mais negativas nos atributos analisados, indicando perdas na qualidade físico-hídrica.

\section{AGRADECIMENTOS}

Ao Consselho Nacional de Desenvolvimento Científico e Tecnológico - CNPq, pelo apoio financeiro, ao Programa de Pós-Graduação em Agronomia da Universidade Federal de Roraima e aos revisores e editor chefe da Revista Brasileira de Ciência do Solo pelas críticas e sugestões.

\section{LITERATURA CITADA}

ALVES, M.C.; SUZUKI, L.G.A.S. \& SUZUKI, L.E.A.S. Densidade do solo e infiltração de água como indicadores da qualidade física de um Latossolo Vermelho distrófico em recuperação. R. Bras. Ci. Solo, 31:617-625, 2007.

AMARO FILHO, J.; ASSIS JÚNIOR, R.N. \& MOTA, J.C.A. Física do solo: Conceitos e aplicações. Fortaleza, Universidade Federal do Ceará, 2008. 290p.
ARAÚJO, E.A. Qualidade do solo em ecossistema de mata nativa e pastagens na Região Leste do Acre, Amazônia Ocidental. Viçosa, Universidade Federal de Viçosa, 2008. 233p. (Tese de Doutorado)

ARSHAD, M.A. \& MARTINS, S. Identifying critical limits for soil quality indicators in agroecosystems. Agric. Ecosyst. Environ., 88:153-160, 2002.

BARBOSA, R.I. Distribuição das chuvas em Roraima. In: BARBOSA, R.I.; FERREIRA, E.J.G. \& CASTELLÓN, E.G., eds. Homem, ambiente e ecologia no Estado de Roraima. Manaus, INPA, 1997. p.325-335.

BARROS, L.S.; VALE JÚNIOR, J.F.; SCHAEFER, C.E.G.R. \& MOURÃO, M. Perdas de solo e água em plantio de Acácia mangium Wild em Savana de Roraima, Norte da Amazônia. R. Bras. Ci. Solo, 33:235-475, 2009.

BENEDETTI, U.G.; VALE JÚNIOR, J.F.; SCHAEFER, C.E.G.R. MELO, V.F. \& UCHÔA, S.C.P. Gênese, química e mineralogia de solos derivados de sedimentos pliopleistocênicos e de rochas vulcânicas básicas em Roraima, Norte Amazônico. R. Bras. Ci. Solo, 35:299-312, 2011.

CARNEIRO, M.A.C.; SOUZA, E.D.; REIS, E.F.; PEREIRA, H.S. \& AZEVEDO, W.R. Atributos físicos, químicos e biológicos de solo de cerrado sob diferentes sistemas de uso e manejo. R. Bras. Ci. Solo, 33:147-157, 2009.

CAVALIERI, K.M.V.; TORMENA, C.A.; VIDIGAL FILHO, P.S.; GONÇALVES, A.C.A. \& COSTA, A.C.S. Efeitos de sistemas de preparo nas propriedades físicas de um Latossolo Vermelho distrófico. R. Bras. Ci. Solo, 30:137147, 2006.

COSTA, F.S.; ALBUQUERQUE, J.A.; BAYER, C.; FONTOURA, S.M.V. \& WOBETO, C. Propriedades físicas de um Latossolo Bruno afetadas pelos sistemas de plantio direto e preparo convencional. R. Bras. Ci. Solo, 27:527-535, 2003.

COSTA, N.L.; GIANLUPPI, V. \& MORAES, A. Morfogênese de Trachypogon vestitus submetido a queima durante o período seco nos cerrados de Roraima. Ci. An. Bras., 13:41-48, 2012.

CRUZ, A.C.R.; PAULETTO, E.A.; FLORES, C.A. \& SILVA, J.B. Atributos físicos e carbono orgânico de um Argissolo Vermelho sob sistemas de manejo. R. Bras. Ci. Solo, $27: 1105-1112,2003$

CRUZ, P.G. Produção de forragem em Brachiaria brizantha: Adaptação, geração e avaliação de modelos empíricos e mecanicistas para estimativa do acúmulo de forragem. São Paulo, Escola Superior de Agricultura "Luiz de Queiroz", 2010. 103p. (Tese de Doutorado)

EMPRESA BRASILEIRA DE PESQUISA AGROPECUÁRIA EMBRAPA. Centro Nacional de Pesquisa de Solos. Sistema brasileiro de classificação de solos. 3.ed. Brasília, Embrapa, 2013. 353p.

EMPRESA BRASILEIRA DE PESQUISA AGROPECUÁRIA EMBRAPA. Centro Nacional de Pesquisa de Solos. Manual de métodos de análise de solo. 2.ed. Rio de Janeiro, 1997. $212 \mathrm{p}$

FLORES, J.P.C.; ANGHINONI, I.; CASSOL, L.C.; CARVALHO, P.C.F.; LEITE, J.G.D.B. \& FRAGA, T.I. Atributos físicos do solo e rendimento de soja em sistema plantio direto em integração lavoura-pecuária com diferentes pressões de pastejo. R. Bras. Ci. Solo, 31:771-780, 2007. 
GIAROLA, N.F.B.; TORMENA, C.A. \& DUTRA, A.C. Degradação física de um Latossolo Vermelho utilizado para produção intensiva de forragem. R. Bras. Ci. Solo, 31:863-873, 2007.

LEÃO T.P. Intervalo hídrico ótimo em diferentes sistemas de pastejo e manejo da pastagem. Piracicaba, Escola Superior de Agricultura Luiz de Queiroz, 2002. 58p. (Dissertação de Mestrado)

LIMA, C.L.R.; REICHERT, J.M.; REINERT, D.J.; SUZUKI, L.E.A.S. \& DALBIANCO, L. Densidade crítica ao crescimento de plantas considerando água disponível e resistência à penetração de um Argissolo Vermelho distrófico arênico. Ci. Rural, 37:1166-1169,2007

MARTINS, S.G.; SILVA, M.L.N.; CURI, N.; FERREIRA, M.M.; FONSECA, S. \& MARQUES, J.J.G.S.M. Perdas de solo e água por erosão hídrica em sistemas florestais na região de Aracruz (ES). R. Bras. Ci. Solo, 27:395-403, 2003.

MELO, V.F.; GIANLUPPI, D. \& UCHÔA, S.C.P. Características edafológicas dos solos do Estado de Roraima. Boa Vista, DSI/UFRR, 2004. 46p.

MORAES, J.F.L.; VOLKOFF, B. \& CERRI, C.C. Soil properties under Amazon forest and changes due to pasture installation in Rondônia, Brazil. Geoderma, 70:60-81, 1996.

NEVES JÚNIOR, A.F. Avaliação da qualidade física de solo em pastagens degradadas da Amazônia. Piracicaba, Escola Superior de Agricultura Luiz Queiroz, 2005. 66p. (Dissertação de Mestrado)

OLIVEIRA, T.K.; MACEDO, R.L.G.; SANTOS, I.P.A.; HIGASHIKAWA, E.M. \& VENTURIN, N. Produtividade de Brachiaria brizantha (Hochst. ex A. Rich.) Stapf cv. Marandu sob diferentes arranjos estruturais de sistema agrossilvipastoril com eucalipto. Ci. Agrotec., 31:748-757, 2007.
RIBEIRO JÚNIOR, J.I. Análises estatísticas no SAEG - Guia prático. Viçosa, MG, Universidade Federal de Viçosa, 2004. $301 \mathrm{p}$.

SANTANA, M.B.; SILVA SOUZA, L.; DUARTE SOUZA, L. \& FONTES, L.E.F. Atributos físicos do solo e distribuição do sistema radicular de citros como indicadores de horizontes coesos em dois solos de Tabuleiros Costeiros do Estado da Bahia. R. Bras. Ci. Solo, 30:1-12, 2006.

SILVA, A.J.N. Efeito de sistemas de uso e manejo nas propriedades físico-hídricas de um Argissolo Amarelo de Tabuleiro Costeiro. R. Bras. Ci. Solo, 29:833-842, 2005.

SILVA, R.R.; SILVA, M.L.N. \& FERREIRA, M.M. Atributos físicos indicadores da qualidade do solo sob sistemas de manejo na bacia do alto do Rio Grande - MG. R. Ci Agrotec., 29:719-730, 2005.

SILVEIRA, D.C.; MELO FILHO, J.F.; SACRAMENTO, J.A.A.S. \& SILVEIRA, E.C.P. Relação umidade versus resistência à penetração para um Argissolo Amarelo distrocoeso no Recôncavo da Bahia. R. Bras. Ci. Solo, 34:659-667, 2010.

SOUZA, M.I.L. Qualidade físico-hídrica de um Argissolo Vermelho-Amarelo sob agroecossistema e floresta natural em Roraima. Boa Vista, Universidade Federal de Roraima, 2010. 91p. (Dissertação de Mestrado)

TAYLOR, H.M.; ROBERSON, G.M. \& PARKER Jr., J.J. Soil strength-root penetration relations to medium to coarse-textured soil materials. Soil Sci., 102:18-22, 1966.

VALE JÚNIOR, J.F. \& SCHAEFER, C.E.G.R. Solos sob Savanas de Roraima: Gêneses, classificação e relação e relações ambientais. Boa Vista, Gráfica Ioris, 2010. $219 \mathrm{p}$. 